\title{
Managing a live music performance: A supply-side analysis
}

\begin{abstract}
Authors:
Bianca Manners ${ }^{1}$

Melville Saayman ${ }^{1}$

Martinette Kruger ${ }^{1}$

Affiliations:

${ }^{1}$ TREES, North-West

University, Potchefstroom

South Africa

Correspondence to:

Melville Saayman

Email:

melville.saayman@nwu.ac.za

Postal address:

TREES, North-West

University, Potchefstroom

2531, South Africa

Dates:

Received: 20 Jan. 2014

Accepted: 09 Dec. 2014

Published: 30 Mar. 2015

How to cite this article:

Manners, B., Saayman, M. \&

Kruger, M., 2015, 'Managing

a live music performance:

A supply-side analysis', Acta

Commercii 15(1), Art. \#252,

11 pages. http://dx.doi.

org/10.4102/ac.v15i1.252

\section{Copyright:}

(C) 2015. The Authors.

Licensee: AOSIS

OpenJournals. This work is

licensed under the Creative

Commons Attribution

License.
\end{abstract}

Purpose and objective: The purpose of this research is to determine what managers regard as important critical success factors in ensuring a memorable visitor experience at a live music performance.

Problem investigated: When organising a live music performance, it is evident that the various characteristics that form part of the visitor experience have to be considered. The critical success factors of live music performances from the supply side are fundamental, since the costs of organising live music performances are high, the needs of the visitors are constantly changing and competition plays a major role in the success of such events. Management furthermore constantly needs to be aware of the ever-changing external environment by determining what factors visitors consider to be vital for a rewarding experience at a major music event. This is extremely important since the concept of experience has become more pervasive, mainly given that the event sector, such as live music performances, has adopted experience as a tool to make individual businesses more competitive, as the organisations operating within this sector exist to provide consumers with an experience.

Design and/or methodology and/or approach: A qualitative research method, by means of interviews, was used to obtain the relevant information from the selected participants. All the data collected in the process were transcribed into text and presented in narrative form. The six steps of data analysis and interpretation were applied to analyse the data.

Findings and impications: The following four major themes emerged from the analysis; each theme was differentiated in terms of various categories and subcategories. Theme 1: The most important aspects for a memorable visitor experience; Theme 2: Main purpose when organising a live music performance; Theme 3: Important aspects regarding the management of a live music performance; Theme 4: Timing of event management. Based on the research conducted on the critical success factors from a supply side, the following findings emerged. Firstly, it is evident that the critical success factors differ significantly from one tourism sector to another. Therefore, more qualitative research should be applied with regard to critical success factors in other tourism operations. Secondly, comparing the results of the qualitative research reveals significantly more in-depth information than those of the various quantitative research studies conducted on critical success factors. Thirdly, it is evident that the pre-event, during-event and postevent planning phases differ from event to event. Lastly, it is evident that there is no common guideline with regard to creating a memorable visitor experience.

Conclusion: Determining the critical success factors for memorable live music performances (from the supply side) in South Africa enables management to improve the current management plans in order to ensure an outstanding memorable visitor experience whilst also improving the overall success rate.

\section{Introduction}

Events can be fun, add richness to the lives of those attending, provide entertainment, be competitive, be intellectually stimulating and can furthermore engender community or national pride (Mair 2009:4). According to Craven and Golabowski (2001:4), Getz (2007:403), Allen et al. (2008:17) and Tassiopoulos (2010:4), the event sector is a relatively young and dynamic sector that is expanding and maturing with its own practitioners, suppliers and professionals, and in which tourists represent a potential market for planned events. This is also the case in South Africa where Paul Simon was one of the first major international artists to tour South Africa in 1992 after a long period of cultural isolation (Big Concerts 2010). This was followed by a flow of various international artists, performers and bands performing in the country. Therefore, managing live music performances is still a very young sector in South Africa. This industry is nevertheless growing rapidly. During an interview with SAfm, Justin van Wyk, CFO of Big Concerts (one of the largest live music promoters in South Africa), stated that an amount of 
R970 million was generated by live music performances held after the 2010 Soccer World Cup at stadia in South Africa (SAfm 2013). Apart from the economic value of these events, there are various additional benefits generated from organising a live music performance, such as promoting the destination and building the image of an attraction, increasing tourist visits, promoting the arts and music, supporting artists and performers, creating business opportunities, contributing to an economic impact, expanding the tourist season and creating job opportunities (Allen et al. 2008:64; Bowdin et al. 2006:38; Brown, Var \& Lee 2002:273; Page \& Connell 2009:602; Saayman 2004:72-73; Sonder 2004:18; Walker \& Walker 2011:275).

Managing live music performances requires a great deal of planning, organising, leading, controlling resources, coordinating and communicating on many levels in order to achieve specific objectives (Hyatt 2008:178; Saayman 2009:59:60; Silvers 2010:50). Kruger and Saayman (2012:183) define a live music performance as 'a performance event comprising one live performance (or an additional live performance, usually in the form of a supporting artist or band) of a specific music genre (such as rock, pop, classical, etc.), usually over a few hours ( $3-5$ hours) on one day in a specific venue and/or city that attracts over 20000 attendees, which is packaged as a coherent whole'. It is evident from this definition that live music performances are part of a complex industry owing to the number of people who have to be managed within a short period. Therefore, according to Sonder (2004:18), the hiring of professional event planners to orchestrate the events is extremely important due to the increased need for security and additional responsibilities. Managing an event is furthermore an intense and difficult task that requires common sense, imagination and experience (Silvers 2012:50). Silvers (2012:50) adds that a manager's job in essence is to determine what requirements have to be satisfied, finding skilful people who are enthusiastic and capable of performing the duties at the event, ensuring that each person is acquainted with their job and, after everything is finished, de-rigging the venue and departing. Consequently, the development strategies of managers include the formulation of plans and decision-making based on the study of hard data and innovative approaches (Silvers 2012:53). The latter is predominantly evident at live music performances as two events might seem similar, but what may work at one may not necessarily work at the other (Adams 2008:200).

Experience has always been an important aspect of the entertainment industry (Pine \& Gilmore 1998:99). According to Andereck et al. (2006:96), the experience of visitors at an event, such as a live music performance, is affected by the setting and the expectations created by the visitor as well as by the organisers in the time leading up to the event. Various management aspects therefore add to a memorable experience as not only the performance is sold to the individual who attends a live music performance, but the entire experience as well, which starts in the pre-event planning phase (when marketing occurs and tickets are bought), through the planning phase (when the actual event is attended) and ending at the post-event planning phase (when the individuals leave the venue). When referring to a memorable visitor experience, it can be defined as the comprehension of the 'wow' factor at an event that is worth remembering once the event is concluded (Manners, Saayman \& Kruger 2014). Critical success factors for a memorable experience from a supply side can be a combination of pre-event, duringevent and post-event managing strategies, which include: planning, leading, marketing, designing, budgeting and control, risk management, logistics, staging and evaluation, providing lighting, sound systems and special effects, entertainment, food and beverages, stalls, entrances, visitors, transport, information, layout, accommodation, financial services, parking, staff, emergency and medical services, safety and security, ticket sales, directions, infrastructure and the venues themselves (Allen et al. 2005:160; Allen et al. 2008:453; Bowdin et al. 2006:535; Matthews 2008:151; Silvers 2004:41).

According to Saayman (2004:151), the financial success of events lies within the framework of the interaction between the event (organisation or management, suppliers, performers or artists, products and themes), the sponsors and the audience, as each role player has goals that are satisfied by the other role players. Customers are the individuals who pay and are necessary for generating an income. Therefore, cautious targeting and attention to customer satisfaction are vital, in conjunction with cost and revenue management (Saayman 2004:153). Due to the importance of satisfying visitor requirements, most researchers have focused on determining the needs of these visitors. However, research currently neglects the views of event managers. In this regard, research on the supply side is essential as it may differ from what the demand side requires from events with regard to a memorable visitor experience. Therefore, the purpose of this research is to determine what managers (supply side) regard as important critical success factors in order to ensure a memorable visitor experience at a live music performance. This research therefore answers questions such as:

- How do managers define a memorable experience?

- What is the main purpose for organising a live music performance?

- What aspects do managers regard as important when organising a live music performance?

- What aspects are important in the pre-event, duringevent and post-event planning phases?

The answers to these questions will enable one to better conceptualise the important critical success factors for a memorable visitor experience from a supply side.

\section{Literature review}

Managing events is creatively and emotionally rewarding; however, apart from this, it is imperative that event management should be approached from a business 
perspective (Silvers 2010:63). Event management is very similar to general or project management, with the difference being the context, as there is a unique aspect of assembling the tangible components that create the intangible product of an event experience (Silvers 2010:50). Tassiopoulos (2000:40) defines event management as follows: 'to manage or control event resources on a given activity, within time, cost and performance requirements.' Tum, Norton and Wright (2006:10) state that the different aspects within the event industry have their own distinctive structures and characteristics. According to Page and Connell (2009:642), event management can be described as the practical aspects of preparing for and staging events. Therefore, it is necessary for event managers to understand and embrace the social nature of an event organisation, as well as to develop leadership skills and attitudes in themselves and those whom they manage (Silvers 2010:63). There are many different events that are produced for various reasons and purposes, but in every case there is an intention to create or at least shape the individual and create mutual experiences for the audience (Getz 2012:30).

These actions vary according to the kind of event that is organised; therefore, in order for the entertainment guide to be common in nature, general activities such as pre-event, during-event and post-event activities are mentioned (Singh 2009:97-98). In the next section, the various aspects relevant in the pre-event, during-event and post-event process planning will be discussed.

\section{Pre-event planning}

The pre-event management stage, which is the first stage of the event lifecycle, is often the longest and involves up to $90 \%$ of the duration of the total event (Emery 1997). According to Shone and Parry (2010:72), this entails the planning of an event and is vital to the success of the event since it has unusual requirements and is a complex process. During this process, according to Packer, Small and Darcy (2008:13-14), the focus of event organisers often remains on the setting of the location and on the management of the critical success factors, rather than catering to the needs of the visitors attending the event.

\section{During-event planning}

According to Westerbeek et al. (2005:36), the second key stage of the proposed event management lifecycle is the implementation process. Emery (1997) found that this stage involves approximately $1 \%$ of the duration of the total project and more than $95 \%$ of the workforce is involved during the event. Westerbeek et al. suggest that the ideal event, in essence, will be the one that leads to total satisfaction of all internal and external stakeholders: a memorable experience, run in a smooth, safe and enjoyable manner in which all parties would wish to be involved again. According to the latter, the interactive nature of attendees at a live music performance with the environment means that many uncertainties exist on the day of the event; this is where performance measures need to be continually monitored and controlled and should take place throughout the event and not just during the implementation stage.

\section{Post-event planning}

The post-event evaluation stage of certain events overlaps with the implementation stage of the events. This phase is concerned with the evaluation and clean-up activities. All the activities in this phase are associated with the previous stages when the event has concluded, the event attendees will have departed and the final undertakings need to be initiated (Westerbeek et al. 2005:153). According to Oriade, Robinson and Gelder (2010:109), the clear-away substage of an event does not only relate to clearing away rubbish and returning the facility to its former glory, it also refers to the importance of the exit of the attendees of the live performance as well as the other stakeholders at the event. They add that the final memory of an event must not be ruined by long delays and traffic jams due to the full volume of traffic leaving the facility at the same time; such problems are unlikely to occur at the start of an event because the attendees arrive over periods of three to four hours prior to the performance.

When referring to critical success factors, Dickinson, Ferguson and Sircar (1984:49) describe them as factors that are derived from, or depend upon, features of both a company's internal and external operating environments, and may arise from a wide variety of issues, circumstances, conditions or activities that require the special attention of the company's organiser. Therefore, according to Slabbert and Saayman (2003:8), critical success factors are those factors that affect the ability of an organisation to prosper in the marketplace, which entails particular strategy elements, product attributes, resources, competencies, competitive capabilities and business outcomes that spell the difference between profit and loss. According to Van der Westhuizen (2003:210), Seetharaman, Sreenivasan and Boon (2006:689) and Kruger (2006:62), identifying critical success factors, in this case for a live music performance, will assist in optimising concerns such as effectively allocating resources, optimising the approach to live music events, offering more target-oriented marketing, improving the event on a continuous basis, formulating and achieving appropriate goals and objectives for each event, meeting visitor needs and expectations, creating a unique or memorable visitor experience, enhancing the management of high-quality services and products, making positive wordof-mouth recommendations and ensuring that live music performances become sustainable in the long term.

Therefore, it has become critical that the events industry, regardless of the size of the event, improves its management so as to fulfil the holistic needs of visitors who attend various events (Richie, Mules \& Uzabeaga 2008). This can be accomplished by determining the critical success factors at these events, from both the demand and the supply sides. However, little research has been conducted at live music performances, specifically from a supply side, to identify such aspects that would create a memorable experience at live 
music performances. Nonetheless, studies on critical success factors have been conducted at different tourism operations. One such study conducted internationally was performed by Lade and Jackson (2004), who focused on the critical success factors of regional festivals in Australia. These authors found that creative and unique programme development each year and appropriate responses to patrons' feedback are considered to be important. Other studies conducted on critical success factors are those by Van der Westhuizen (2003) at a guesthouse, Kruger (2006) at a conference centre, De Witt (2006) at a wedding event and Getz and Brown (2006) in wine tourism regions. The results of the various studies displayed in Table 1 are arranged in order of importance based on the results of a statistical analysis conducted in each study.

In Table 1, it is evident that various managers at different tourism operations regard certain aspects to be more important than others. Therefore, it is important to note that none of the tourism operations can follow the same guidelines with regard to management aspects to ensure effective management, as each tourism sector differs. In addition, none of the studies in Table 1 determined the important aspects (critical success factors) for management and what management would regard as important for creating a memorable visitor experience at a live music performance. This is the first time, to the authors' knowledge, that such research has been conducted from a supply side, specifically focusing on live music performances and reviewing the pre-event, during-event and post-event planning phases as well as what contributes to a memorable visitor experience from the supply side. Due to these three elements, the specific aspects are currently unknown and therefore are often approached as universal management strategies when organising events. By identifying what management regards as important for managing a live music performance, in particular, will contribute significantly to more improved live music performances, effective pre-event, during-event and post-event management strategies and an understanding of what managers regard as important to create a memorable experience.

\section{Method of research}

A qualitative research method was the most appropriate research method to obtain the relevant information from the selected participants. According to Durrheim (2006), qualitative researchers collect data in the form of written or spoken language and analyse the data by identifying and categorising themes based on the research method. This research methodology is concerned with understanding the processes and the social and cultural contexts that underlie various behavioural patterns and the emphasis is mostly on the quality and depth of information rather than on the scope or breadth of the information provided, as witnessed in quantitative research (Niewenhuis 2008a:51).

\section{Research design}

The research followed a case study approach. Merriam (1998:27) describes the qualitative case study method as 'an intensive, holistic description and analysis of a single instance, phenomenon, or social unit'. Bromley (1991:302) adds that a case study is a 'systematic inquiry into an event or a set of related events which aims to describe and explain the phenomenon of interest'. According to Niewenhuis (2008b:75), typical characteristics of a case study are that it strives towards a holistic understanding of how participants relate to one another and interact in a specific situation and how they make meaning of a specific phenomenon that is under study. Therefore, the reason for employing case studies is that they emphasise an individual unit, group or organisation. A case study ensures that the researcher gains a better understanding of the meanings attached by those within the system. In this case, five managers were involved from various companies that organise live music performances.

\section{Participants}

All the participants shared a common feature in that they were all involved in organising and managing live music performances. In qualitative research, the experiences and expected views of participants are more significant than their numbers (Cresswell 2009:185-189). In this regard, based on the data drawn from a study by Guest, Bunce and Johnson (2005:59), it was found that saturation occurs within the first 12 interviews, although basic elements for meta-themes were evident as early as in the first 6 interviews. Since the live music performance sector is growing rapidly in South Africa, a diverse number of suitable representative companies were chosen for this research. Therefore, only five participants were selected who organise live music performances, which include both national and international artists, on a large scale (see Table 2 for the background of participants). The experience of possible candidates for this research was based on the scale of events that they have organised, the artists and events that they have previously managed and the number of individuals that they have managed at each event. With this in mind, a purposeful sampling method was used and five participants were identified (see Table 2).

\section{Data collection}

A structured interview was used to collect the data for this research. According to Nieuwenhuis (2008b:87), a structured interview within the qualitative research method is used in multiple case studies to ensure structure and the questions are detailed and developed in advance as, for example, in a survey research. Open-ended and closed-ended questions were used to ascertain the socio-demographic information of the managers organising the live music events and included questions that determined their gender, age, job description, company profile, the types of events they had organised, the main target audiences of those events and the previous events that had been organised. The questions posed during the interviews were general and broad with regard to what the managers considered to be important aspects in ensuring a successful and memorable event. The questions were also designed to obtain a general profile of each manager. 


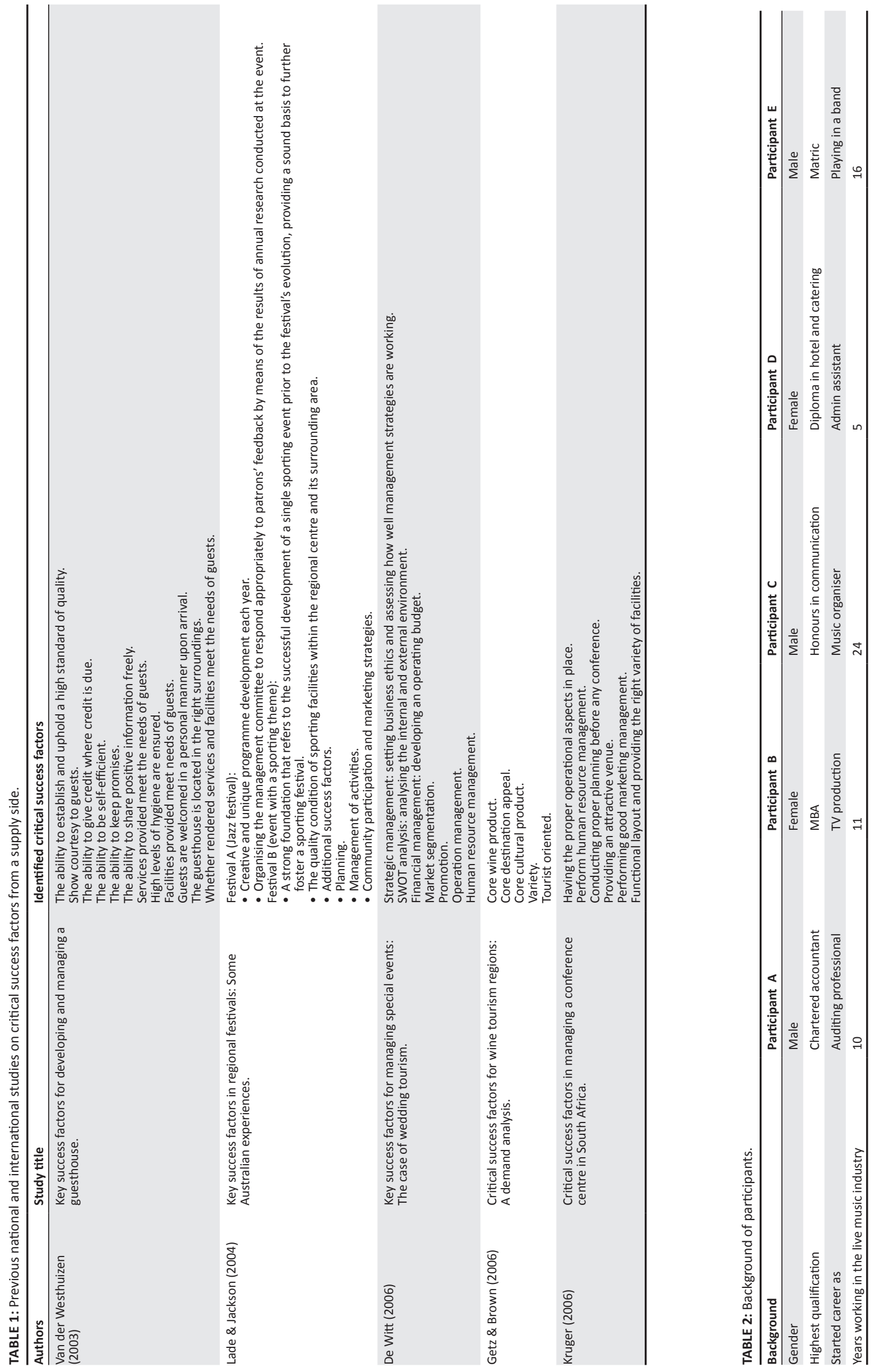


These questions served as guidelines and allowed the various managers to identify what they individually considered to be the important aspects regarding each of the management factors that they had identified. Based on the responses, follow-up questions were formulated. All the interviews were audiotaped and transcribed and subsequently the interactions of the individuals during the interviews were studied.

\section{Data analysis}

The data collected during the process of this research project were transcribed into text and presented in narrative form. Cresswell's six steps in data analysis and interpretation were used to analyse the data. The various stages are:

- Step 1: Organise and prepare the data. During this step, the data were organised and prepared for analysis, which involved the transcription of the recorded interviews.

- Step 2: Read through all the data. A general sense of the information was obtained during step 2 by reading through the data several times in order to reflect upon the overall meaning, specifically with regard to the management aspects reflected in the results.

- Step 3: Begin a detailed analysis with a coding process. The data with regard to the important management aspects were coded in order to identify the important management aspects. Thereafter, a recode process was followed by an outsider in order to ensure trustworthiness. The results were then compared to one another in order to gain an overall perspective.

- Step 4: Use the coding process to generate a description of the setting or people as well as categories or themes for analysis. In this research, the various codes were then divided into categories, whereafter themes were allocated to each category. These themes appear as the major findings in the results and were used to create headings in the findings section of this study.

- Step 5: Advance how the description and themes will be represented in the qualitativenarrative. A discussion followed that mentioned the chronology of the importance of the various themes identified. This step conveys descriptive information about each theme and the information identified by each participant.

- Step 6: A final step in data analysis involves making an interpretation or meaning of the data. Lastly, personal interpretation and understanding were formulated with regard to the results gained from this resarch, which was then compared to previous research and literature based on the supply side when organising an event, and specifically live music performances.

\section{Issues of trustworthiness}

In qualitative research, trustworthiness is an indication of 'methodological soundness and adequacy' (Holloway \& Wheeler 2002:254). Trustworthiness for this research was accomplished by means of peer examination as well as coding and recoding of the data.

\section{Ethical consideration}

Ethical approval was obtained from the Ethics Committee of the North-West University (Potchefstroom campus: NWU00115-12-A4). The main purpose of research ethics is to protect the welfare of the research participants (Wassenaar 2006). Therefore, ethical considerations were taken into account by respecting the rights, needs, values and desires of the participants (Cresswell 1994). Consent was obtained from all five participants before the interviews were conducted. The different parties were requested to grant permission where permission was requested, thereby ensuring informed and voluntary participation. All participants were informed that their identity would be protected and that they could withdraw from the research project at any time.

\section{Results}

Four major themes emerged from the analysis of the data. Each theme was differentiated in terms of various categories and subcategories. Appropriate verbatim quotations from the transcribed interviews are provided as validation. Some of the participants did not have a very good command of the English language, as is evidenced in some of the quotations.

\section{Theme 1: The most important aspects for a memorable visitor experience}

According to Participant A, there are multiple aspects that contribute to a memorable experience: 'There are multiple aspects ... I would say the most important aspect is first and foremost that the artists come on stage. That is probably the most important part.' Participant B added:

'I want to say their performance, but then again if people are enjoying themselves you know then sometimes it becomes almost secondary. ... I do think the actual performance ... it's not necessarily I've been at concerts where I really didn't like the type of music, but it's really about how the band interacts with the audience and the vibe.' (Female, MBA, TV production)

Participant D added to this aspect:

'I would say it is the personal interactions. That is why his fans try always to sit in the front five rows. ... You can't walk to the back of the venue and interact with everyone.' (Female, Diploma in hotel and catering, Admin assistant)

Participant A asserted:

'food and beverages are available. I would also say that there are clean and ample amounts of toilets. And I would say that the access in and out of the venue is sufficient.' (Male; Charered accountant, Auditing professional)

Participant B commented on an important aspect for creating a memorable visitor experience:

'I think staff at the premises is very important and that starts with the car guards at the car park to the people at the ticket office, information staff, the people checking the tickets as they go in, that flow from the car, the concert area is important. ... I think even if people have to wait long and so on in queues, the fact that the staff was polite and friendly is welcoming and all 
of that makes a big difference ... getting all of their expectations is probably ... the fact that if you say the gates will open at four they know the gates will open at four. That sort of thing to at least manage their expectation, and then to communicate well with them in advance.' (Female, MBA, TV production)

Participant E commented on important aspects for a memorable experience:

'It must be something that you want to see. ... I don't think people go to concerts that they don't want to see. And then it must be a ... You don't want to have issues while ... or during it ... you want to get to your drinks easily, you wanna go to the loo easily.' (Male, matric, Playing in a band)

Therefore, it is evident that aspects relating to a memorable experience are that the artist actually appears on stage to perform and then the unexpected interaction with the crowd. Additional key aspects raised here that contribute to a memorable experience were friendly staff, good communication with the individuals who attend the event, clean and adequate ablution facilities and the fact that the various aspects such as food and beverages are easily accessible.

However, when participants were asked to define the term 'memorable experience', Participant A commented: 'It is just memorable that the artist goes on stage, and deliver a performance that meet expectation.' Participant B commented on the term as follows:

'Obviously it's so individual for each visitor. ... I think that make a concert unique are memorable visitor experiences like a band that does something that a ... they haven't done it in other concerts or bring on a guest artist ... things that are sort of unexpected on the day, however these are not things that sell the show, they happen on the day ... it is just the sort of elements or something that you couldn't have experienced anywhere else. ... I think it is that unexpected elements that you actually generally can't control, some surprise ... but that's what get people talking and they will remember that.' (Female, MBA, TV production)

Participant D added to the meaning of a memorable experience:

'I think the most memorable would be the fans' reactions. Some shows people just sit there and they are quiet, you know reserved. And I think if you have a show where people respond and you can really feel the energy in the show that would be a memorable thing ... gets very personal. ... People will stand up and move around and cry. So I think that is where it becomes memorable.' (Female, Diploma in hotel and catering, Admin assistant)

Participant E concluded the discussion on a memorable experience as follows:

'When you walk out of there and you're singing the song that you just heard, and you feel like you're on cloud 9, then you were at a good concert, then I think the job was done well.' (Male, matric, Playing in a band)

Therefore, when one considers the term memorable experience, it is evident that the needs of individuals are difficult to determine as the individuals attending the live music performances cannot be regarded as homogeneous. However, a memorable performance would be one that meets the needs of the audience and offers some sort of uniqueness that will be distinctive to a specific event. Therefore, unexpected elements such as an interaction with the artist or some sort of element of surprise are significant. It is also important to get the fans talking about the event in order to make it worth remembering.

\section{Theme 2: Main purpose when organising a live music performance}

Participant A clearly stated making money as the main purpose for organising a live music performance. This appears to be obvious since Participant A has a chartered accounting background. However, apart from this, Participant $\mathrm{C}$ with an honours degree in communication, also supported Participant A's statement: 'If you are a producer, the main purpose is to make as much money as possible! It is not called Show Business without a reason.' Participant D (diploma in hotel and catering) stated that 'suppose we do shows mainly because it is the main income' whereas Participant E, with only a matric, stated: 'It depends on what angle you look at it - you know, obviously we running a business, so we want to make money by doing so.' Therefore, it is evident that generating money is the main reason for organising a live music performance.

\section{Theme 3: Important aspects regarding the management of a live music performance}

Four aspects were identified as important regarding the management of a live music performance. In order of importance, these are: artist, audience, marketing and media and technical aspects. Each of these subthemes is discussed individually.

\section{Artist}

The artist at the concert seemed to be the most important aspect regarding the management of a live music performance. Various participants indicated that one should feature the right artist for the event, as Participant B commented:

'To actually have a line up where everybody can say "wow there is something I want to see here" ... the mix is very important, putting that whole puzzle together that you don't have say two jazz concerts in a row; that there is a nice flow from one genre to the other $\ldots$ and that big names and smaller ones are mixed up nicely. But at the same time one has to look at, at artists' availability and their international tours.' (Female, MBA, TV production)

This is important, as Participant C remarked: 'Right artist for your target market.' This statement is supported by Participant E: 'Without a band you not gonna have a show.... But I think if you want to really narrow it down and you need a band,' Furthermore, participants also indicated that the artist must be happy, as Participant A contended: 'The artist must be happy.' Clearly, featuring the right artist as well as 
assuring their happiness during the event are both important aspects in organising a live music performance.

\section{Audience \\ Based on the interviews, an audience also appears to be very important for various participants in terms of organising a live music performance, as Participant E commented: 'You need a band and you need people to hear them play.' Since this participant started his career as a member of a band, the importance of an audience is understood not only from a business perspective, but also from the viewpoint of the band. However, apart from just the presence of an audience at a live music performance, Participant B stated that the experience of the audience should also be managed: \\ 'Manage that whole experience of, of visitors because you can have a great concert but people can have a bad experience because they ... their car got broken into, or ... they had to walk too far to the concert area or a staff member was rude to them, so there are so many little aspects that one has to manage along the way or even when they phoned in to inquire about ticket sales and got the wrong information and so on.' (Female, MBA, TV production)}

This view is supported by Participant A, who asserted: 'There must be audience satisfaction.'

\section{Marketing and media}

With regard to marketing and media, Participant D stated that 'marketing is probably the most important other thing'. This is supported by Participant C who claimed marketing to be important in organising a live music performance. The importance of this aspect for Participant $C$ can be supported by the fact that he holds an honours degree in communications and has been working in the music industry for 24 years, which is the longest period compared to all the other participants. Therefore, the importance of marketing is evident as a considerable amount of experience in this field is essential. Furthermore, Participant A commented that 'there must be media appraisal' when organising a live music performance.

\section{Technical aspects}

Interestingly, only two of the respondents commented on technical aspects as being important in organising a live music performance. Participant D stated: 'The main thing is to have good technical personnel.' This view is also supported by Participant $C$ who remarked: 'Experienced people to run technical.' This is important as it may have a direct impact on the success of the actual performance of the artist.

\section{Theme 4: Timing of event management}

During the planning process of organising a live music performance, the phases of pre-event, during-event and post-event planning take place. Throughout each phase, various managers regard certain aspects as more important than others. The important aspects of each planning process are discussed individually in the next section.

\section{Pre-event planning}

Various event managers considered certain aspects to be important during the pre-event planning stage. Participant D described pre-event planning as: 'Like the critical things like the venue, obviously that's important.' Participant E added: 'You obviously start with having to find a place [location].' This view is supported by Participant C who suggested that the venue has to be secured. According to Participant B, various aspects regarding the artist are important, as Participant B commented: 'Well first of all the most important would be finalising a deal with them and getting a contract which mean the, a negotiating a rate, negotiating a date.' Participant A remarked: 'during pre-production we would focus on all of the paper reader requirements from the artist's side.' Participant C commented that 'technical' is secured during the pre-event management stage, as did Participant D. Contracts and aspects regarding the law were also mentioned as important aspects relating to the pre-event planning phase. Participant $\mathrm{C}$ mentioned that contracts are important, whereas Participant A indicated the law as an aspect that takes up significant time in organising a live music performance: 'Then also the compliance with the laws and bylaws of the events industry as a whole. That is what we spend the most time on pre-event.' Apart from the actual law, Participant $C$ indicated ticketing to be important. Participant $\mathrm{B}$ added that ticket sales are also important: 'Ticket sales ... get the concert sold out so it's all the marketing that goes with it.' Marketing is supported by Participant B who further added that the 'general concept marketing ... also have specific marketing'. Participant C commented that there must be a 'marketing plan in place', whilst Participant D replied: 'Marketing is important.' Safety and security were indicated by Participant A as being important: 'Pre-event is really about ensuring the safety and security of people attending the event.' Participant E confirmed that the date on which the event takes place is important to select, and based on whether aspects such as the date, venue and artist are in place, the budget could be calculated:

'Depending on what kind of show it is, you obviously start with having to find a place ... a date, a venue, an artist. ... Then you do the budget based on those ... depending on the venue.' (Male, Matric, Playing in a band)

Therefore, it is evident that during the pre-event management phase of organising a live music performance aspects such as the venue, the artist, the technical, contracts and aspects regarding the law, ticketing, marketing, safety and security and the date of the event are considered to be important by the various managers.

\section{During-event planning}

Participants indicated that the during-event planning phase is about the actual implementation of the all the plans, as Participant C commented: 'Implementing of all plans - you have to have experienced managers to help you execute all the different disciplines - artist management, technical, security, logistics.' Participant A remarked that: 
'During the actual event it is about the execution [of] the plans. It is also about the various safety and security [plans] coming together. It's the coordination of security services, ushers, police, health and safety officials and environmental health. Also this includes beverages, throughout the duration of the day, cleaning staff, all of these kinds of things are important during the process.' (Male, Chartered accountant, Auditing professional)

\section{Participant B added that:}

\begin{abstract}
'On the day the important thing is that everything runs smoothly for the visitor's experience, there are no ... delays at the ticket office ... there are ushers in the concert area guiding people where do they need to go and so on just that everything runs smoothly on the day, that the information staff is informed and doing their job and so on. So it's then just basically the flow of, of people and making sure they get to where they need to be in a pleasant as possible way.' (Female, MBA, TV production)
\end{abstract}

Therefore, according to the various participants, the duringevent planning phase revolves around the implementation of all the plans that have to be attended to.

\section{Post-event planning}

Most of the participants indicated that post-event planning comprises debriefing as Participant A commented that 'not much goes on post planning, about debriefing and if there were any note issues that will be discussed and recommendations are made to ensure that these aspects are addressed'. Participant $C$ further remarked about 'post mortem meeting $[s]$ to discuss problems and how to avoid problems in the future'. Due to the number of people that Participant A deals with on a regular basis, it is evident that debriefing of the event is significant to him. However, Participant B referred to specific details about ensuring that the event concludes successfully and that both the fans and artists are satisfied, that is, 'an important thing for us here is that the band and I think it is not only with us, it is all over the world, but the band stops performing when they need to stop performing'. Participant B added:

'that 'after the concert it is also the people leaving the concert area ... the traffic department working closely with us ... to get the people out of the area ... once the traffic flow from there that's where the traffic department comes in to make sure the roads are cleared ... so that people don't sit in a queue.' (Female, MBA, TV production)

\section{Apart from this, Participant B also remarked:}

\begin{abstract}
'if there are complaints about anything if something went wrong ... it rains out policy is the concert always goes ahead irrespective of rain, but there are always people that don't understand that and say "I want a refund", but just managing it, that sort of communication, ... try to give them comps to another concert or so, but just you ... manage someone that's unhappy after the concert.' (Female, MBA, TV production)
\end{abstract}

Furthermore, Participant $C$ added activities such as: 'paying everyone, de-rigging of venue, recon of all expenses and income.' Therefore, it is evident that during the post-event planning phase the following aspects are considered to be important by the various managers: debriefing, concluding the performance of the band or artist, traffic control, handling complaints, making and ensuring that all payments are executed and de-rigging the venue.

\section{Findings and implications}

Firstly, based on the research conducted on the critical success factors from a supply side, it is evident that the critical success factors differ significantly from one tourism sector to another. This is evident when one compares the results of this study to research conducted by Lade and Jackson (2004), Van der Westhuizen (2003), Kruger (2006), De Witt (2006) and Getz and Brown (2006). It was found that making money or generating revenue is considered by the various managers to be the main purpose for organising a live music performance. Whether the managers work for a privately owned company or an organisation that is funded by government, generating revenue is the main purpose for organising live music performances. This, however, could have implications as managers could lose focus of the important aspects relating to ensuring a memorable visitor experience as their focus may fall mainly on ways to generate more revenue instead of ensuring that the visitors are satisfied with what is being offered at the event. This argument is confirmed when one reviews the critical success factors. The artist was identified as the most important critical success factor; however, none of the previous research conducted on critical success factors identified this aspect as being important. Technical aspects were identified as another critical success factors in this study, but were also not identified in previous research. This amplifies the fact that none of the tourism sectors can be regarded as the being the same, as certain aspects are rated more important than others. Regarding audience expectation and satisfaction, it is evident that this factor must be present in various tourism sectors. This notion is supported by Van der Westhuizen. Marketing and media were also identified as an important aspect, which is supported by the findings of Lade and Jackson, De Witt and Kruger. Therefore, when referring to the critical success factors, it is evident that certain critical success factors are specific to a particular sectors in tourism. Therefore, it is recommended that when educating future event and specifically live music performance managers, attention should be on this factor. Further research should therefore be conducted at other events in order to investigate different events. Apart from this, it is also important to compare all the differences. This will not only contribute to event-specific education, but also enhance existing literature on this topic and add to more event-specific management in the future.

Secondly, comparing the results of the qualitative research reveals significantly more in-depth information than those of the various quantitative research studies conducted on critical success factors. This research followed a qualitative research approach, whereas the research conducted by Lade and Jackson (2004), Van der Westhuizen (2003), Kruger (2006), De Witt (2006) and Getz and Brown (2006) followed 
a quantitative research approach. The results are more in depth due to the freedom that respondents have when qualitative research is applied: they are free to comment more openly to questions during the interview, whereas quantitative research restricts the respondents to aspects captured in a structured questionnaire. Therefore, more qualitative research should be applied with regard to critical success factors in other tourism operations to gain more indepth information on aspects that are regarded as important in running a successful tourism operation.

Thirdly, it is evident that the pre-event, during-event and post-event planning phases differ from event to event. In addition, during each of the phases, managers differed in terms of which critical success factors they regarded as important. This finding could be due to the different environments that the event managers work in; for example, Participant B does not have to organise a venue for live performances as the venue is part of the setting she works in and she has access to the venue at all times, whereas Participants A, C, D and E do not have access to a permanent venue. Therefore, these managers have to secure a venue that is adequate for any specific live music performance they organise. With this in mind, it may be significant to investigate aspects that differ in terms of organising an event that has a structured venue as opposed to one where the venue has to be built or rented. This may add to the in-depth information in the future, which could, in turn, broaden the field of live music performances. In addition, it could also enhance current literature on managing live music performances. Therefore, it is recommended that future research be carried out on the management aspects of the pre-event, during-event and post-event management aspects where a structured venue is in place, compared to where a venue has to be built or rented.

Lastly, based on this research, it is evident that there is no common guideline with regard to creating a memorable visitor experience. According to the respondents, a memorable experience is created by the performance of the artist who actually appears on stage to perform as well as their unexpected interaction with the crowd. Various other aspects were also identified that contribute to a memorable experience, such as friendly staff, good communication with the individuals who attend the event, clean and adequate ablution facilities and the fact that the various aspects such as food and beverages are easily accessible. Furthermore, the aim of a performance should be to fulfill the requirements of the individuals who attend. An element of uniqueness, surprise and interaction with the artist could therefore be significant in ensuring a memorable experience for the attendee. Therefore, when comparing the elements of a memorable visitor experience with the critical success factors identified in this study (i.e. artist, audience, marketing and technical aspects), it is evident, according to the managers, that there is more to organising an event than just making money; it is also about the smaller details and providing basic individual satisfaction. This is a difficult task as each individual differs and respondents cannot be regarded as homogeneous, but there are basic aspects that can be offered to ensure a memorable experience for those attending a live music performance. This could either be achieved by an unexpected element, an interaction with the artist or a surprise element that was added to the performance or event. The key is for managers to constantly investigate ways to keep people talking and surprise them with elements that would cause them to talk about the event.

\section{Conclusion}

This research determined what managers regard as important critical success factors in ensuring a memorable visitor experience at a live music performance. This was the first time that this type of research was applied to management aspects from a supply side in terms of managing a live music performance. The results indicated the following to be important when organising a live music performance: artist, audience, marketing and media and technical aspects. In addition, three contributions were made: firstly, it was the first time that research was conducted based on the critical success factors for a memorable visitor experience from a supply side; secondly, a qualitative research approach was used, also for the first time; thirdly, this research contributed greatly towards gaining detailed information on the main purpose for organising a live music performance, what aspects managers regard as important when organising a live music performance, what aspects are important in the pre-event, during-event and post-event planning phases and how managers define a memorable experience.

With regard to creating a memorable visitor experience, it is important for management to take note of the importance of aspects such as friendly staff, good communication with the individuals who attend the event, clean and adequate ablution facilities and the fact that the various aspects such as food and beverages are easily accessible. These aspects are all important, but aspects such as providing an element of uniqueness, surprise or interaction with the artist can also enhance a memorable experience. Therefore, with reference to the definition of a memorable experience offered by Manners et al. (2014), it could be defined as a comprehension of the 'wow' factor at an event that is worth remembering once the event has been concluded. An elaboration of this definition could specify that a memorable experience is an understanding that is created where the needs of individuals who attend an event are satisfied and a performance is delivered that exceeds the expectations of the attendees, ensuring that, in the end, the fans will talk about the event and that it will be worth remembering. This understanding could either be created by an unexpected element, an interaction with the artist or a surprise element that was added to the performance or event.

\section{Acknowledgements}

The authors would like to thank Big Concerts and all the participating respondents for being willing to take part 
in this research project. They would also like to thank the National Research Foundation (NRF) for financial assistance; the research would not have been possible without their support.

\section{Competing interests}

The authors declare that they have no financial or personal relationship(s) that may have inappropriately influenced them in writing this article.

\section{Authors' contributions}

This research forms part of B.M.'s (North-West University) $\mathrm{PhD}$ in Tourism Management whilst M.S. (North-West University) and M.K. (North-West University) were respectively her promoter and co-promoter.

\section{References}

Adams, L.J., 2008, 'Conclusions', in C. Mallen \& L.J. Adams (eds.), Sport, recreation and tourism event management: Theoretical and practical dimension, pp. 199-203, Butterworth-Heinemann, Oxford. http://dx.doi.org/10.1016/B978-0-7506-84477.00012-2

Allen, J., O'Toole, W., Harris, R. \& McDonnell, I., 2008, Festival and special event management, 4th edn., Wiley, Milton.

Allen, J., O'Toole, W., McDonnell, I. \& Harris, R., 2005, Festival and special event management, 3rd edn., Wiley, Milton.

Andereck, K., Bricker, K.S., Kerstetter, D. \& Nickerson, N.P., 2006, 'Connecting experiences to quality: Understanding the meanings behind visitor's experiences', in G. Jennings \& N.P. Nickerson (eds.), Quality tourism experiences, pp. 81-111, Elsevier, Oxford. http://dx.doi.org/10.1016/B978-0-7506-7811-7.50012-2

Big Concerts, 2010, Neil Diamond live for the first time ever in South Africa, viewed March 30, 2011, from http://www.bigconcerts.co.za/media centre/press release/2010/october/Neil\%Diamond\%200fficial\%ress\%20Release.pdf

Bowdin, G., Allen, J., O’Toole, W., Harris, R. \& McDonnell, I., 2006, Event management, 2nd edn., Elsevier, Oxford.

Bromley, D.B., 1991, 'Academic contributions to psychological counselling: A philosophy of science for the study of individual cases', Counselling Psychology Quarterly 3(3), 299-307. http://dx.doi.org/10.1080/09515079008254261

Brown, M.D., Var, T. \& Lee, S., 2002, 'Messina Hof Wine and Jazz Festival: An economic impact analysis', Tourism Economics 8(3), 273-279. http://dx.doi. org/10.5367/000000002101298115

Craven, R.E. \& Golabowski, L.J., 2001, The complete idiot's guide to meetings and event planning, Alpha Books, Indianopolis, IN.

Creswell, J.W., 1994, Research design: Qualitative and quantitative approaches, Sage Thousand Oaks, CA.

Cresswell, J.W., 2009, Research design: Qualitative, quantitative, and mixed methods approach, 3rd edn., Sage, Thousand Oaks, CA.

De Witt, L., 2006, 'Key success factors for managing special events: The case of wedding tourism', MCom dissertation, TREES, North-West University.

Dickinson, R.A., Ferguson, C.R. \& Sircar, S., 1984, 'Critical success factors and small business', American Journal of Small Business 8(3), 49-57.

Durrheim, K., 2006, 'Research design', in M. Ter Blanche, K. Durrheim \& D. Painter (eds.), Research in practice: Applied methods for the social sciences, 2nd edn pp. 33-54, UCT Press, Cape Town.

Emery, P.R., 1997, 'The management of major sport events', MBA dissertation, Durham University.

Getz, D., 2007, Event studies: Theory, research and policy for planned events, Elsevier, Oxford.

Getz, D., 2012, 'Event studies', in S.J. Page \& J. Connell (eds.), The Routledge handbook of events, pp. 27-46, Routledge, New York.

Getz, D. \& Brown, G., 2006, 'Critical success factors for wine tourism regions: A demand analysis', Tourism Management 27(1), 146-158. http://dx.doi.org/10.1016/j. tourman.2004.08.002

Guest, G., Bunce, A. \& Johnson, L., 2005, 'How many interviews are enough? An experiment with data saturation and variability', Field Methods 18(1), 59-82. http://dx.doi.org/10.1177/1525822X05279903

Holloway, I. \& Wheeler, S., 2002, Qualitative research in nursing, Blackwell, Oxford.
Hyatt, C., 2008, 'Facilitating quality in event management', in C. Mallen \& L. Adams (eds.), Sport, recreation and tourism event management, pp. 165-179, Elsevier, (eds.), Sport, recreation and tourism event management, pp. 165-179,
Burlington, MA. http://dx.doi.org/10.1016/B978-0-7506-8447-7.00010-9

Kruger, M.E., 2006, 'Key success factors in managing a conference centre in South Africa', MCom dissertation, TREES, North-West University.

Kruger, M. \& Saayman, M., 2012, 'Listen to your heart: Motives for attending Roxette live', Journal of Convention and Event Management 13(3), 181-202. http://dx.doi. org/10.1080/15470148.2012.715996

Lade, C. \& Jackson, J., 2004, 'Key success factors in regional festivals: Some Australian experiences', Event Management 9(1), 1-11. http://dx.doi. org/10.3727/1525995042781066

Mair, J., 2009, 'The events industry: The employment context', in B. Thomas, M. Deery, C. Hanlon, L. Lockstone \& K. Smith (eds.), People \& work in events \& conventions: A research perspective, pp. 3-16, CABI Publishing, Cambridge. http://dx.doi org/10.1079/9781845934767.0003

Manners, B., Saayman, M. \& Kruger, M., 2014, "Managing the "wow factor" at live music performances, African Journal of Hospitality, Tourism and Leisure 3(2), music perf.

Matthews, D., 2008, Special event production: The process, Butterworth-Heinemann, Oxford.

Merriam, S.B., 1998, Qualitative research and case study applications in education, Jossy-Bass, San Francisco.

Nieuwenhuis, J., 2008a, 'Introducing qualitative research', in K. Maree (ed.), First steps in research, pp. 47-68, Van Schaik, Hatfield.

Nieuwenhuis, J., 2008b, 'Qualitative research designs and data gathering techniques', in K. Maree (ed.), First steps in research, pp. 69-97, Van Schaik, Hatfield.

Oriade, A., Robinson, P. \& Gelder, S., 2010, 'Delivering live events', in P. Robinson, D. Wale \& G. Dickson (eds.), Events management, pp. 72-112, CABI International, Cambridge.

Packer, T., Small, J. \& Darcy, S., 2008, Tourist experiences of individuals with vision impairment, viewed May 17 2011, from http://www.crctourism.com.au/wms/ upload/Resources/90044 Packer_TourismVisionlmpaired WEB \%281\%29.pdf

Page, J.P. \& Connell, C., 2009, Tourism: A modern synthesis, 3rd edn., Cengage Learning EMEA, Hampshire.

Pine, J. \& Gilmore, J.H., 1998, 'Welcome to the experience economy', Harvard Business Review 98407, 97-105.

Ritchie, B., Mules, T. \& Uzabeaga, S., 2008, Visitor attractions satisfaction benchmarking project, viewed May 17 2011, from http://www.crctourism.com. au/wms/upload/Resources/90069_Richie_AttSatbenchmarking WEB.pdf

Saayman, M., 2004, An introduction to sports tourism and event management, 2nd edn., Institute for Tourism and Leisure Studies, Potchefstroom.

Saayman, M., 2009, Hospitality, leisure and tourism management, 2nd edn., Institute for Tourism and Leisure Studies, Potchefstroom.

SAfm, 2013, Press release, viewed July 25 2013, from http://www.moneyweb.co.za/ moneyweb-special-report/justin-van-wyk--cfo-big-concerts

Seetharaman, A., Sreenivasan, J. \& Boon, L.P., 2006, 'Critical success factors of a total quality management', Quality and Quantity 1(40), 675-695. http://dx.doi. org/10.1007/s11135-005-1097-2

Shone, A. \& Parry, B., 2010, Successful event management: A practical handbook, 3rd edn., Cengage Learning, Andove.

Silvers, J., 2004, Professional event co-ordination, Wiley, Hoboken, NJ.

Silvers, J., 2010, Events management body of knowledge project: The Event Genre of event management, viewed May 14 2013, from http://www.juliasilvers.com/ embok

Silvers, J., 2012, 'The role of management in events management', in D. Tassiopoulos (ed.), Events management: A developmental and managerial approach, 3rd edn., Juta Education, Lansdowne.

Singh, S.R., 2009, Event management, APH Publishing Corporation, New Delhi.

Slabbert, E. \& Saayman, M., 2003, Guesthouse management in South Africa, 2nd edn., Institute for Tourism and Leisure Studies, Potchefstroom, South Africa.

Sonder, M., 2004, Event entertainment and production, Wiley, Upper Saddle River, NJ.

Tassiopoulos, D., 2000, 'Events: An introduction', in D. Tassiopoulos (ed.), Event management, pp. 3-33, Juta Education, Lansdowne.

Tassiopoulos, D., 2010, Events management: A development and managerial approach, Juta Education, Lansdowne, South Africa.

Tum, J., Norton, P. \& Wright, J.N., 2006, Management of event operations, Elsevier/ Butterworth-Heinemann, Oxford, UK/Burlington, MA.

Van der Westhuizen, T., 2003, 'Key success factors for developing and managing a guesthouse', MCom dissertation, TREES, North-West University.

Walker, J.R. \& Walker, J.T., 2011, Tourism concepts and practices, Prentice Hall, Upper Saddle River, NJ.

Wassenaar, D.R., 2006, 'Ethical issues in social science research', in M. Ter Blanche, K. Durrheim \& D. Painter (eds.), Research in practice: Applied methods for the social sciences, 2nd edn, pp. 33-54, UCT Press, Cape Town.

Westerbeek, H., Smith, A., Turner, P., Emery, P., Green, C. \& Van Leeuwen, L., 2005, Managing sport facilities and major events, Routledge, London. 